\title{
Québec. La réforme éducative entre intention et
} réalité

Études de cas

\section{Clermont Gauthier}

\section{(Q) OpenEdition}

\section{Journals}

Édition électronique

URL : https://journals.openedition.org/ries/1267

DOI : 10.4000/ries. 1267

ISSN : 2261-4265

Éditeur

France Education international

Édition imprimée

Date de publication : 1 décembre 2005

Pagination : 54-56

ISSN : 1254-4590

Référence électronique

Clermont Gauthier, «Québec. La réforme éducative entre intention et réalité », Revue internationale d'éducation de Sèvres [En ligne], 40 | décembre 2005, mis en ligne le 17 novembre 2011, consulté le 05 juillet 2021. URL : http://journals.openedition.org/ries/1267 ; DOI : https://doi.org/10.4000/ries.1267

Ce document a été généré automatiquement le 5 juillet 2021

(c) Tous droits réservés 


\section{Québec. La réforme éducative entre intention et réalité}

Études de cas

Clermont Gauthier

1 En Occident, l'école fait face habituellement à des critiques sévères, à la mesure des attentes élevées de la société à son égard. Le système d'éducation québécois, modernisé de fond en comble au début des années 1960, remanié à la pièce depuis lors, commençait, selon plusieurs critiques, à subir l'épreuve du temps et se devait d'être réexaminé dans son ensemble.

\section{Une concertation démocratique}

2 C'est ainsi que les États généraux sur l'éducation, vaste consultation populaire menée à l'échelle du Québec au cours des années 1995-96, ont vu le jour (ministère de l'Éducation, 1996a, 1996b).

3 La Commission des États généraux a présenté un premier rapport traçant un portrait de la situation (ministère de l'Éducation 1996a), qui a été suivi d'un second (ministère de l'Éducation, 1996b) identifiant dix chantiers prioritaires pour rénover le système d'éducation. La refonte des programmes des écoles primaires et secondaires était l'un de ces chantiers. Un groupe de travail a par la suite été mandaté pour jeter les bases de la réforme du curriculum. Son rapport (ministère de L'éducation, 1997a) a servi d'assise à l'énoncé officiel de politique éducative L'école, tout un programme (ministère de l'Éducation, 1997b) qui lançait officiellement la réforme. Le nouveau programme de formation de l'école québécoise résulte de ces consultations (ministère de l'Éducation, 2001).

4 La détermination de la mission éducative et des contenus que l'école doit transmettre aux nouvelles générations fait partie des débats qu'une société doit conduire. C'est là le rôle du politique au sens positif du terme et les États généraux sur l'éducation ont été un exemple de l'expression démocratique. 


\section{Des décisions contradictoires}

Il semble cependant y avoir eu un décalage important entre la phase consultative et de première mise en forme de la réforme, d'une part, (ministère de l'Éducation, 1996a, 1996b, 1997a, 1997b) et le document de programme qui a été produit en fin de course, d'autre part (ministère de l'Éducation, 2001). En effet, le document de réforme des programmes est allé beaucoup plus loin que les conclusions du rapport des États généraux sur l'éducation et les orientations proposées par le groupe de travail sur la réforme du curriculum. Les réflexions sur les finalités de l'école, sur les contenus du curriculum ont, curieusement, cédé le pas à un ensemble de prescriptions pédagogiques. C'est même sur cet élément de la pédagogie que le ministère a choisi d'orienter toute sa campagne de communication en proclamant qu'il faut désormais " passer du paradigme de l'enseignement au paradigme de l'apprentissage », paradigme selon lequel les activités d'enseignement prennent notamment la forme de projets réalisés en équipe par les élèves placés dans des situations complexes d'apprentissage.

\section{Les résultats de la recherche ignorés}

6 C'est cependant sur ce plan précis du choix des moyens pédagogiques les plus susceptibles de maximiser l'apprentissage que la recherche scientifique est directement interpellée. Celle-ci montre, contrairement aux prétentions ministérielles, que les moyens pédagogiques proposés dans le cadre de la réforme - notamment la pédagogie de projet et les approches par découverte - sont loin d'avoir fait leurs preuves. Ils ne produisent pas les effets escomptés sur l'apprentissage des élèves et, là où ils ont été expérimentés et évalués de manière rigoureuse, ils ont été jugés plutôt décevants.

7 Nous avons abouti à un tel constat au terme d'une analyse approfondie des résultats des recherches empiriques les plus significatives menées ces trois dernières décennies sur l'efficacité comparée de diverses approches pédagogiques ${ }^{1}$. Les études analysées montrent que les approches pédagogiques ne se valent pas toutes et que certaines favorisent mieux les apprentissages scolaires des élèves. Ce sont les procédés pédagogiques faisant appel à une démarche d'enseignement explicite et systématique qu'il ne faut surtout pas confondre avec l'enseignement magistral - qui donnent les meilleurs résultats. L'analyse des études révèle que des propositions pédagogiques analogues à celles qui sous-tendent la réforme québécoise ont conduit à l'augmentation $\mathrm{du}$ taux d'échec des élèves dans les systèmes scolaires où elles ont été implantées. Ce fut le cas en Suisse, en Belgique, au Royaume-Uni et dans plusieurs États américains. En un mot, la réforme québécoise va dans le sens contraire des conclusions de ces travaux de recherche.

8 Il y a plusieurs explications possibles à cette dérive: soit que, dans le processus d'élaboration des programmes, les rédacteurs aient été séduits par la pédagogie de projet en oubliant toutefois la mission essentielle d'instruction que doit poursuivre l'école et qui était pourtant clairement affirmée dans les rapports (1997a, 1997b) qui fondaient la réforme; soit qu'ils ne connaissaient pas l'existence des recherches sur le peu d'efficacité de ces approches pédagogiques dont ils recommandent l'emploi ; soit que, dans la hâte qui a caractérisé le processus d'élaboration des programmes, ils aient tout simplement confondu les genres. Nous l'avons maintes fois remarqué, il arrive très 
souvent, en éducation, que l'on mette dans la même balance l'« essai pédagogique ", le témoignage sincère de l'acteur de terrain et la recherche empirique élaborée selon les critères scientifiques. La recherche en enseignement a confirmé depuis trente ans que la pédagogie de la découverte et l'approche par projet favorisent les élèves forts au détriment des plus faibles et les enfants de familles aisées et de parents ayant un niveau élevé d'instruction. En revanche, l'enseignement dit explicite, direct instruction, les recherches comparatives entre plusieurs pays le montrent, représente sans contredit l'approche qui a donné les meilleurs résultats quant à l'apprentissage des élèves faibles ou venant de milieux défavorisés, sans pour autant pénaliser les autres catégories d'élèves.

9 En éducation, où on a affaire à de jeunes et vulnérables générations, il est nécessaire de redoubler de prudence et éviter l'adhésion prématurée aux idées pédagogiques qui n'ont pas été soumises à des vérifications empiriques. Dans le secteur médical, tout nouveau médicament doit passer par une série de tests avant d'être mis en vente sur le marché. Pourquoi n'en serait-il pas de même en éducation? Les décideurs politiques auront-ils la lucidité (ou le courage) de reconnaître que la réforme du curriculum leur a échappé et qu'entre l'intention initiale et le programme approuvé, il y a eu un décalage important?

\section{BIBLIOGRAPHIE}

Ministère de l'Éducation (2001) : Programme de formation de l'école québécoise. Éducation préscolaire, enseignement primaire. Québec : Gouvernement du Québec.

Ministère de l'Éducation (1997a) : Réaffirmer l'école. Prendre le virage du succès. Rapport du Groupe de travail sur la réforme du curriculum. Québec: Gouvernement du Québec.

Ministère de l'Éducation (1997b) : L'école, tout un programme. Énoncé de politique éducative. Québec : Gouvernement du Québec.

Ministère de l'Éducation (1996a) : Les États généraux sur l'éducation. 1995-1996. Exposé de la situation. Québec : Gouvernement du Québec.

Ministère de l'Éducation (1996b) : Les États généraux sur l'éducation. 1995-1996. Rénover notre système d'éducation : dix chantiers prioritaires. Rapport final de la Commission des États généraux sur l'éducation. Québec : Gouvernement du Québec.

\section{NOTES}

1. Voir S. Bissonnette, M. Richard et C. Gauthier (2005) Échec scolaire et réformes éducatives. Quand les solutions deviennent la source du problème. Presses de l'Université Laval. 
INDEX

Index géographique : Québec

\section{AUTEUR \\ CLERMONT GAUTHIER}

Titulaire de la chaire de recherche du Canada en formation à l'enseignement, faculté des sciences de l'éducation, Université Laval, Québec. 